\title{
Socio-demographic influences on trends of fish consumption during later adult life in the Whitehall II study
}

\author{
Tasnime N. Akbaraly* and Eric J. Brunner \\ Department of Epidemiology and Public Health, University College London, London WC1E 6BT, UK \\ (Received 24 October 2007 - Revised 28 January 2008 - Accepted 28 February 2008 - First published online 29 May 2008)
}

Our aim was to investigate how socio-demographic factors influence trends and age-related trajectories of fish consumption. We examined consumption of total, fried and recommended fish (white and oily fish, and shellfish) in the Whitehall II study over 11 years in participants aged 39-59 years at phase 3 . The cohort included 8358 British civil servants who completed a FFQ at phase $3(1991-3)$, phase $5(1997-9, n 5430)$ and phase 7 (2002-4, $n$ 5692). Occupational grade, ethnicity, marital and retirement status were collected at each phase. To analyse changes in age-related trends of fish intake over time according to socio-demographic characteristics, we applied a random mixed-effect model. Over the follow-up a significant increase in consumption of 'recommended' (mean: 1.85 to 2.22 portions/week) and total fish (mean: 2.32 to 2.65 portions/week) and a decreasing trend in fried-fish intake (mean: 0.47 to 0.43 portions/week) was observed. Recommended, fried and total fish consumption differed by occupational status, ethnicity, marital status and sex. The trend of age-related fish intake diverged significantly by ethnicity. In South Asian participants $(n$ 432), slope of recommended-fish consumption was significantly higher compared with white participants $(0 \cdot 077 v .0 \cdot 025$ portions/week per year). For black participants ( $n$ 275) slope of fried-fish intake was significantly higher compared with white participants $(0.0052 v .-0.0025$ portions/week per year). In terms of public health, our descriptive and analytical work allows detailed understanding of the impact of socio-demographic factors on fish intake and its age-related trends. Such information is valuable for food policies that seek to promote health equity.

Fish-consumption trajectories: Socio-demographic factors: Random-effect models: Prospective studies: Middle age

Regular fish consumption is linked with a decreased risk of several conditions including $\mathrm{CVD}^{(1)}$ and cancer $^{(2,3)}$. Based on its previous review ${ }^{(4)}$, in a context where cardiovascular mortality rate in the UK continued to exceed that of most other Western nations, the Committee on Medical Aspects of Food Policy recommended in 1994 the consumption of two portions (one portion $=140 \mathrm{~g} /$ week) of fish per week of which one should be oily fish ${ }^{(4,5)}$. National Food Survey data shows that consumption of total fish and fish products increased by $13 \%$ in the 20 years after 1979. Average UK consumption of total fish and fish products in 2000 was $143 \mathrm{~g} /$ week, about half the level recommended by the Committee on Medical Aspects of Food Policy ${ }^{(6)}$. The National Diet and Nutritional Survey found that two-thirds of adults did not consume fish or fish dishes during the period of the survey (July 2000-June 2001), indicating they were not regular consumers of white or oily fish ${ }^{(7)}$. Fish consumption, against the benchmark of the healthy eating guideline, remains generally low, with considerable variations across the British population.

To our knowledge, there are no longitudinal studies of fish consumption in the UK or other Western countries, although several surveys have analysed socio-demographic differences in consumption ${ }^{(8-11)}$. It would be useful to know, for example, whether fish consumption was altered since the Department of
Health's recommendations were published, and if such changes are related to socio-economic positions. Differences in nutritional behaviour and food consumption according to social class ${ }^{(12-20)}$ and other socio-demographic characteristics such as age ${ }^{(21)}$, sex ${ }^{(18,22,23)}$, ethnicity ${ }^{(24,25)}$ and marital status $^{(19,26)}$ are well known, but no analyses within a longitudinal framework exist. In terms of public health, such an approach could provide valuable information for food policies that seek to promote health equity. To investigate how sociodemographic factors could influence the trajectories of fish consumption during later adult life, we investigated consumption of fried fish and 'healthy' or 'recommended' fish (white and oily fish, and shellfish) over 11 years in the Whitehall II study, in a prospective cohort of British civil servants.

\section{Subjects and methods}

\section{Population}

The target population for the Whitehall II study was an all London-based office staff, aged 35-55 years, working in twenty civil service departments. The cohort consisted of 10308 participants ( 6895 men and 3413 women) who responded at the first phase in $1985-8^{(27)}$. The cohort was invited to the research clinic at 5-year intervals: phase 3 (1991-3, $n$ 8637), 
phase $5(1997-9, n 7830)$ and phase 7 (2002-4, $n$ 6914); and a postal questionnaire was sent to participants between clinic phases $^{(28)}$. The FFQ was first administered at phase 3 .

\section{Variables}

Food consumption. During the clinic phases, participants were sent a machine-readable $\mathrm{FFQ}^{(29)}$ based on that used in the US Nurses Health study ${ }^{(30)}$. The food list (127 items) in the FFQ was anglicised, and foods commonly eaten in the UK were added ${ }^{31)}$. The number of participants who completed the self-reported questionnaire was 8358, 5430 and 5692 , at phases 3,5 and 7 respectively, which corresponds to a participation rate of $81.1 \%$ for phase $3,52.7 \%$ for phase 5 and $55.2 \%$ for phase 7 . A common unit or portion size for each food was specified, and participants were asked how often, on average, they had consumed that amount of the item during the previous year. The nine responses ranged from 'never or less than once per month' to 'six or more times per day'. The FFQ used at the three different phases were the same regarding fish-consumption items. We considered two types of fish consumption, the 'fried fish' included fried fish in batter such as in fish and chips, fish fingers and fish cakes, and the 'recommended fish' included white fish (fresh or frozen), oily fish (fresh or canned) and shellfish. Total fish was defined by the sum of fried fish and recommended fish.

Socio-demographic variables. Demographic variables such as sex, ethnicity (white/South Asian/black), age and marital status (married/cohabiting or not) were obtained from a general questionnaire. To index the occupational class (low/ middle/high) the participant's civil service employment grade at each phase (current or most recent) was used. Participants were also asked at each phase to classify their employment status, with 'retired' as an option. Thus employment grade, marital and retirement status could vary over time, and the data during the three follow-up phases (3,5 and 7) were updated.

\section{Statistical analyses}

Mean values of intake of total, recommended and fried-fish consumption were calculated and described according to socio-demographic characteristics at each phase. Comparison of socio-demographic variables between participants who completed the FFQ at phase 3 only and those who completed it at all three phases was made using Student's $t$ test when two classes of variable were compared (sex, marital and retirement status) and the Fisher test (ANOVA) when more than two classes (ethnicity and employment grade) were compared.

We used random-effect models (generalised linear mixed models) to analyse longitudinal repeated data, which take into account within-subject correlations. The model allows the within-subject dependency to vary from one participant to another by means of the random part of the co-variable linear combination ${ }^{(32)}$. In the present analyses we introduced a random intercept and a random slope. The random intercept represents the individual variability in fish consumption but constant through time and the random slope corresponds to the individual change of strength of association for each interval of time between two responses. In preliminary models time was considered to be a combination of follow-up duration and age at inclusion. An interaction term between follow-up time and age allowed us to test whether the effect of time was more pronounced in older participants. Because this interaction was negligible, the main analyses used random-effect models in which time was the participant's age at each phase (Appendix 1). So in the repeated current-age variable, the change in age from one phase to the next is identical to change in time. Therefore the coefficient of change in age indicates the time trend in the dependent variable, and the coefficient of change in age crossed with sex (for example) is the differential time trend in the dependent variable for males compared with females. To describe graphically the effect of each socio-demographic variable separately on agerelated food-consumption trajectories, we first modelled each explanatory variable separately, in which time, explanatory variable, and the interaction between time and explanatory variable were included (the estimated coefficients associated to the interaction term expresses the age-related slope of consumption according to the level of explanatory variable). To take into account the effects of all these social characteristics simultaneously, we constructed random-effect models in which all the social characteristics and their interaction with time were included together. Thus, by taking into account the within-subject correlations, these models explain how intake of fried, recommended, total fish and their age-related change during the follow-up could be explained by sex, employment grade, ethnicity, marital and retirement status. Results of random-effect models are expressed by linear regression coefficient $(\beta)$ and standard deviation. All statistical analyses were performed using SAS software version 9.1 (SAS Institute Inc., Cary, NC, USA).

\section{Results}

During the 11-year follow-up, mean values of total fish-intake increased (1991-3, $n$ 8330, 2.32 (SD 1.95) portions/week; 1997-9, $n$ 5323, 2.53 (SD 2.10) portions/week; 2002-4, $n$ 5541, 2.65 (SD 2.01) portions/week). Fig. 1 shows that this increase is mainly due to the increase of oily-fish consumption.

Participants for whom fish-consumption information was collected at the three phases $(n$ 4149) did not differ in their

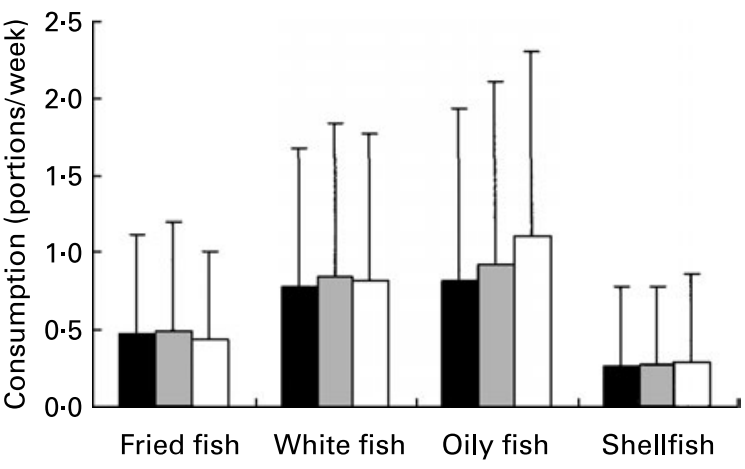

Fig. 1. Change in fish and seafood consumption between 1991 and 2004 Sample consists of all participants, including regular and irregular consu-

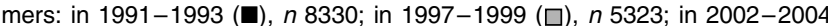
$(\square), n$ 5541. The calendar trends are not age-adjusted. Values are means with standard deviation indicated by vertical bars. 
consumption of total fish or recommended fish (shellfish and oily or white fish) at baseline (phase 3) compared with participants who did not answer at either phase 5 or phase 7 ( $n$ 2131). Baseline consumption of fried fish, proportions of men, white subjects, participants in high employment grades, non retired and married participants were statistically significantly higher in participants who completed the three phases than in participants who did not (results not shown).

At phase 3, mean recommended-fish consumption was 1.84 (SD 1.82) portions/week and mean of fried-fish was 0.47 (SD 0.65 ) portions/week. While $6.7 \%$ of participants reported they never consumed fish, $62.0 \%$ consumed recommended fish at least once per week and $19.0 \%$ consumed fried fish at least once per week.

The comparison of socio-demographic characteristics at phase 3 according to fish consumption patterns (Table 1) showed that a higher proportion of men consumed fried fish at least once per week and recommended fish less than once per week compared with other fish-consumption patterns. A higher proportion of white, high-grade employment, retired or married participants consumed recommended fish at least once per week and fried fish less than once per week. A higher proportion of South Asian or black ethnic participants consumed both fried fish and recommended fish at least once per week. A repeated cross-sectional comparison of means of fried-fish (Appendix Table 1), recommendedfish (Appendix Table 2) and total fish (Appendix Table 3) consumption was described at each phase, according to age group, employment grade, marital status, retirement or ethnic group, in men and women separately. Tables in the Appendix show that, in men particularly, the intake of each category of fish is similar for participants of the same age, regardless of the calendar time, that is, showing no age-matched time trend, which generally reflects methodological differences or society-wide secular trends ${ }^{(33)}$. The only age-matched trend was observed in 55-59 and 60-64-year-aged women for whom an increase of total and recommended-fish intake was observed.

\section{Longitudinal analyses}

Effects of time of follow-up and age. Results of randommodel effects in which time was a combination of age at the initial phase and follow-up duration, showed that fish consumption increased statistically significantly at each phase (Fig. 2 (A)) and increased also with age, but the effect of age did not differ statistically significantly between the three periods as it is graphically represented by the same slope of fish consumption according to age at phase 3 (Fig. 2 (A)).

Effects of other socio-demographic characteristics. In subsequent random-effect models (Fig. $2(\mathrm{~B}-\mathrm{F})$ ), time was the participant's age at each phase. Trajectories of fish consumption were estimated according to employment grade, ethnic group, marital status, retirement status and sex. The effect of each of the social characteristics adjusted for each other is detailed in Table 2. In this complete model, the intercept term ( 0.56 for fried fish, 1.79 for recommended fish and 2.35 for total fish) refers to mean intake in portions per week for the reference group: men aged 39 years, in high-grade employment, nonretired, non-married and white. The slope term refers to trajectories of consumption according to age for the reference group. The positive estimated coefficient observed for recommended and total fish $(\beta=0.025$ and $\beta=0.022$ respectively) indicates increased intake according to age while the negative estimated coefficient associated to fried fish intake $(\beta=-0.0025)$ indicates a decrease of intake with age.

Employment grade. Participants in low-grade employment had a significantly higher intake of fried fish compared with high-grade employment participants (Fig. 2 (B)). A statistically significantly lower consumption of recommended and total fish in low- and middle-grade employment participants was observed compared with those in high-grade employment. The slope's coefficient shows a statistically significant difference in fried fish consumption between participants in middle and high employment grades. The trajectories of recommended and total fish do not differ according to employment grade.

Table 1. Socio-demographic characteristics according to patterns of fish consumption at phase 3 in regular consumers (1991-1993)

\begin{tabular}{|c|c|c|c|c|c|c|c|}
\hline & \multicolumn{2}{|c|}{$\begin{array}{c}\text { Recommended-fish } \dagger \\
\text { consumers } \neq \\
(n 4138,49.7 \%)\end{array}$} & \multicolumn{2}{|c|}{$\begin{array}{l}\text { Fried-fish consumers } \S \\
\quad(n 564,6 \cdot 8 \%)\end{array}$} & \multicolumn{2}{|c|}{$\begin{array}{l}\text { Both recommended- } \\
\text { and fried-fish consu- } \\
\text { mers } \|(n 1023,12 \cdot 3 \%)\end{array}$} & \multirow[b]{2}{*}{$P$ value } \\
\hline & Mean \% & SD & Mean \% & SD & Mean \% & SD & \\
\hline Fried fish (portions/week) & 0.25 & 0.30 & $1 \cdot 29$ & 0.64 & 1.46 & 0.96 & $<0.001$ \\
\hline Recommended fish (portions/week) & $2 \cdot 72$ & 1.83 & 0.44 & 0.36 & $2 \cdot 56$ & 1.82 & $<0.001$ \\
\hline Total fish (portions/week) & 2.98 & 1.84 & 1.73 & 0.75 & 4.02 & $2 \cdot 27$ & $<0.001$ \\
\hline Men $(\%)$ & $65 \cdot 4$ & & $79 \cdot 6$ & & $69 \cdot 9$ & & $<0.001$ \\
\hline High employment grade (\%) & $44 \cdot 2$ & & $26 \cdot 3$ & & 33.4 & & $<0.001$ \\
\hline White (\%) & 93.5 & & $91 \cdot 8$ & & $88 \cdot 3$ & & \\
\hline South Asian (\%) & 2.9 & & $6 \cdot 6$ & & 6.9 & & $<0.001$ \\
\hline Afro-Caribbean (\%) & 3.6 & & 1.6 & & $4 \cdot 8$ & & \\
\hline Married (\%) & $77 \cdot 7$ & & 72.5 & & $73 \cdot 3$ & & 0.003 \\
\hline Retired (\%) & $11 \cdot 1$ & & $9 \cdot 4$ & & $8 \cdot 6$ & & 0.01 \\
\hline
\end{tabular}

${ }^{*}$ For details of procedures, see Subjects and methods.

† White and oily fish, and shellfish.

$\ddagger$ Participants who consume $\geq 1$ portion/week recommended fish and $<1$ portion/week fried fish

$\S$ Participants who consume $\geq 1$ portion/week fried fish and $<1$ portion/week recommended fish.

$\|$ Participants who consume $\geq 1$ portion/week fried fish and $\geq 1$ portion/week recommended fish. 

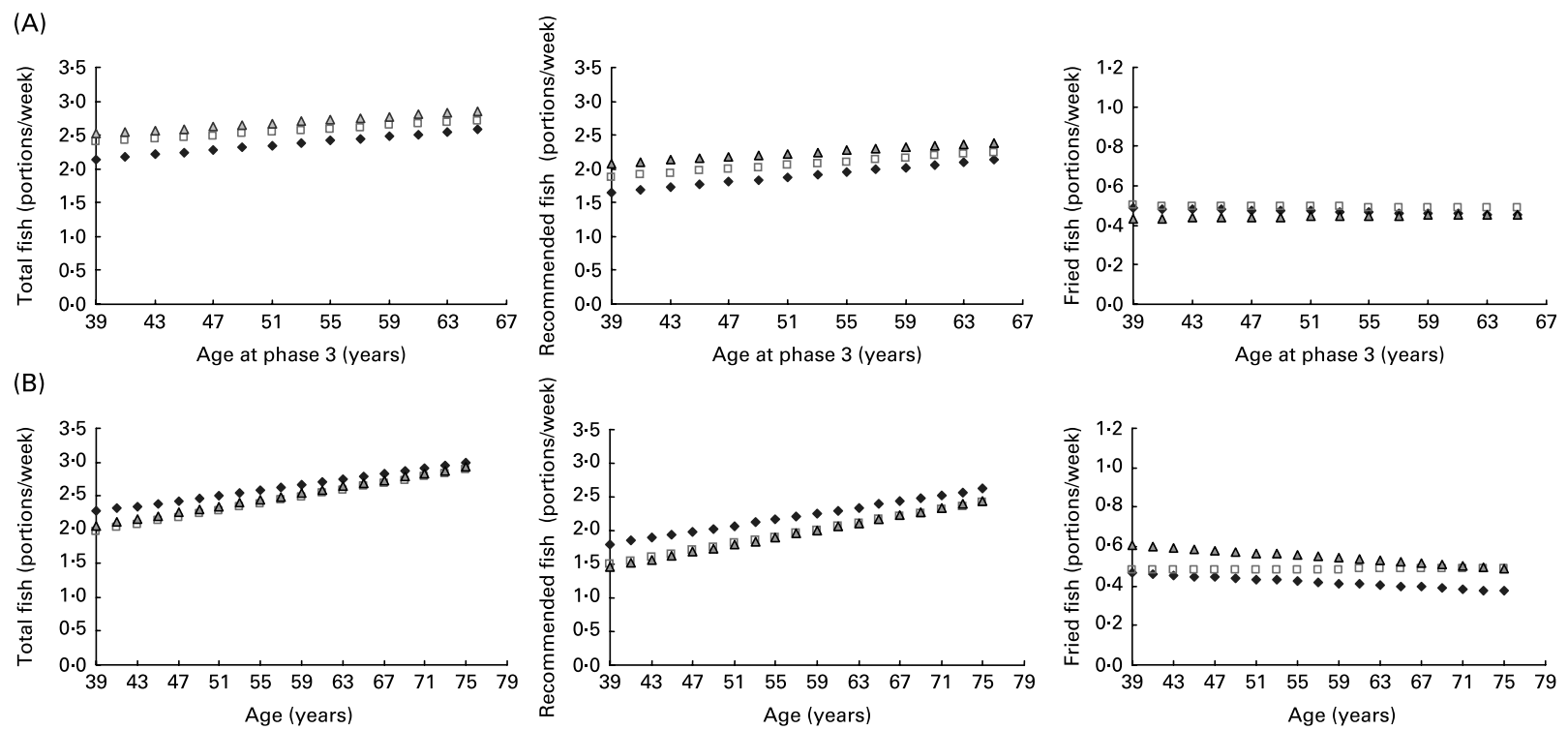

(C)
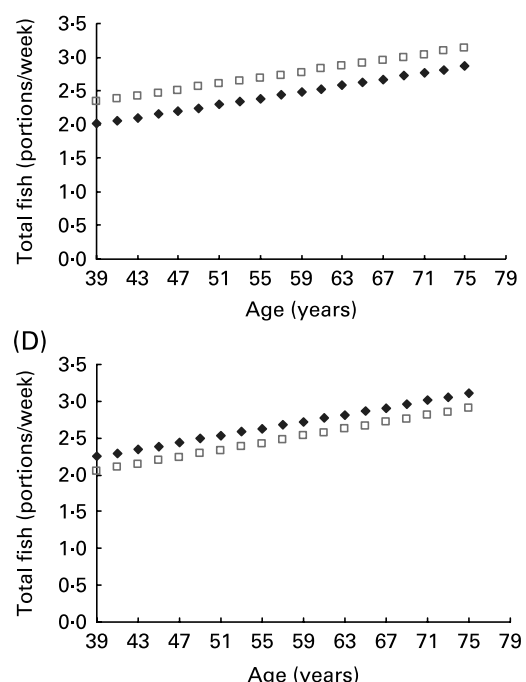

(E)
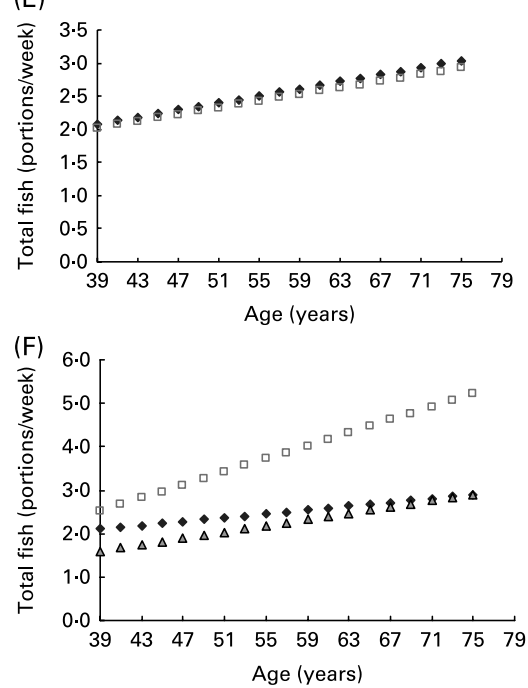
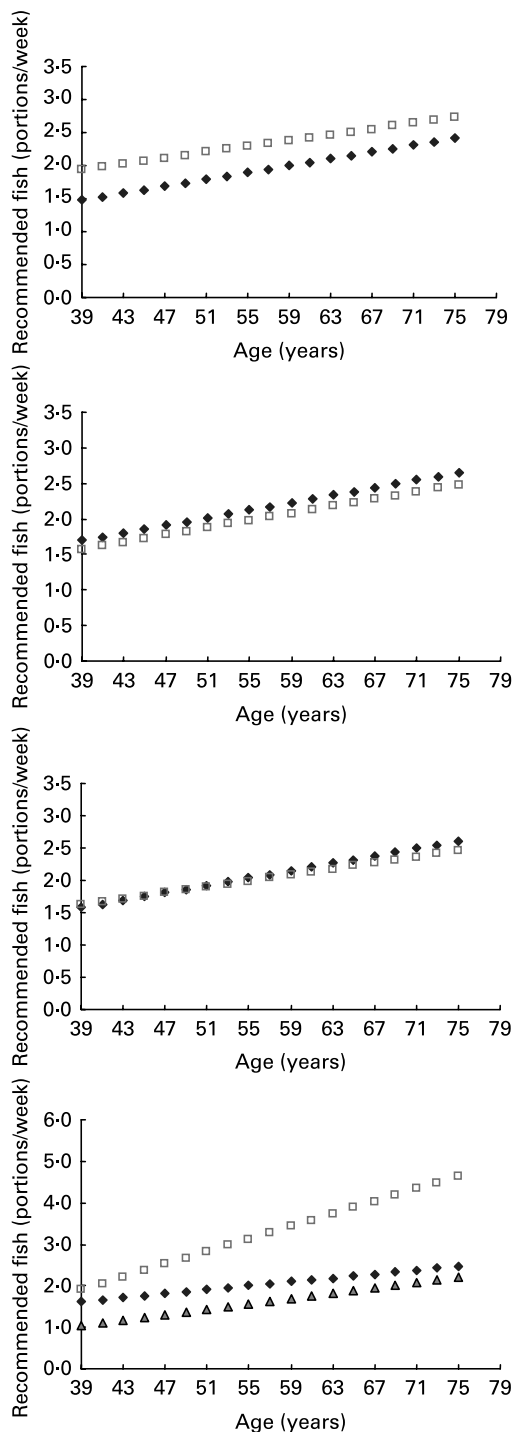
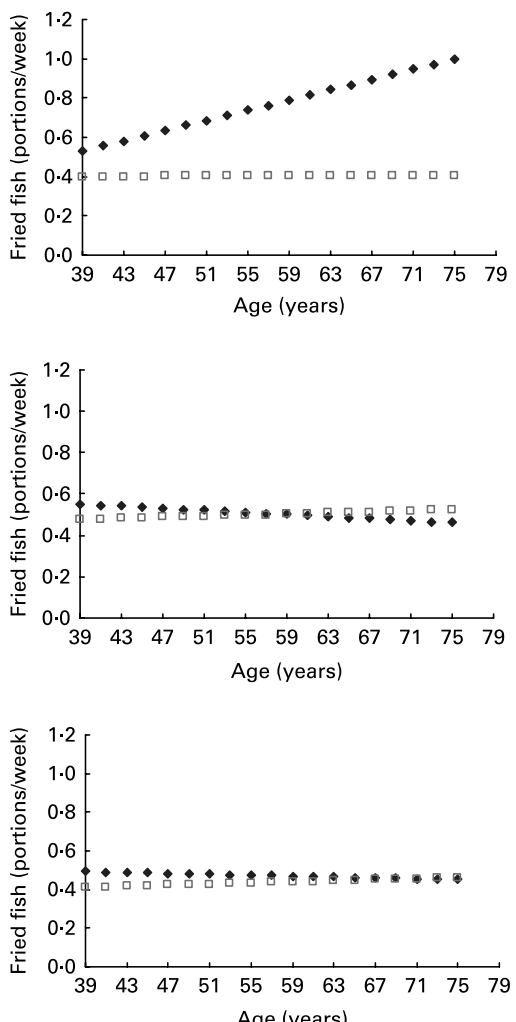

Age (years)

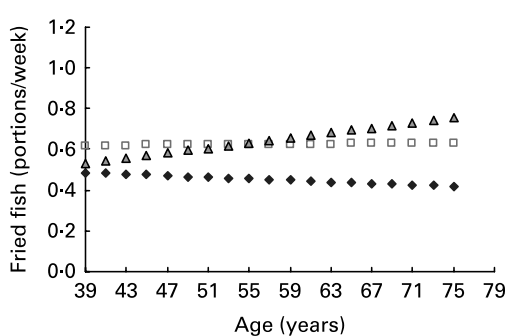

Fig. 2. Trajectories of age-related intake of total, recommended and fried fish by (A) study phase ( $\bullet, 1991-1993 ; \square, 1997-1999 ; \triangle$, 2002-2004), (B) employment grade ( $\bullet$, high; $\square$, middle; $\triangle$, low), (C) sex ( $\bullet$, men; $\square$, women), (D) marital status ( $\bullet$, not married; $\square$, married), (E) retirement status $(\bullet$, not retired; $\square$, retired) and (F) ethnic group ( $\bullet$, white; $\square$, South Asian; $\triangle$, black). 
Table 2. Estimated coefficients $(\beta)$ for fish consumption (fried, recommended and total) and their age-related trajectories after adjustment for all variables*

\begin{tabular}{|c|c|c|c|c|c|c|c|c|c|}
\hline \multirow[b]{3}{*}{ Fixed effects } & \multicolumn{9}{|c|}{ Consumption (portions/week) } \\
\hline & \multicolumn{3}{|c|}{ Fried fish } & \multicolumn{3}{|c|}{ Recommended fish } & \multicolumn{3}{|c|}{ Total fish } \\
\hline & $\beta$ & SD & $P$ & $\beta$ & SD & $P$ & $\beta$ & SD & $P$ \\
\hline Intercept & 0.56 & 0.03 & $<0.001$ & 1.79 & 0.08 & $<0.001$ & 2.35 & 0.08 & $<0.001$ \\
\hline \multicolumn{10}{|l|}{ Employment grade } \\
\hline High & 0 & & & 0 & & & 0 & & \\
\hline Medium & 0.029 & 0.024 & 0.22 & -0.38 & 0.063 & $<0.001$ & -0.35 & 0.069 & $<0.001$ \\
\hline Low & 0.18 & 0.039 & $<0.001$ & -0.65 & $0 \cdot 11$ & $<0.001$ & -0.48 & $0 \cdot 12$ & $<0.001$ \\
\hline \multicolumn{10}{|l|}{ Sex } \\
\hline Men & 0 & & & 0 & & & 0 & & \\
\hline Women & -0.19 & 0.026 & $<0.001$ & 0.58 & 0.071 & $<0.001$ & 0.39 & 0.078 & $<0.001$ \\
\hline \multicolumn{10}{|l|}{ Marital status } \\
\hline Not married & 0 & & & 0 & & & 0 & & \\
\hline Married & -0.075 & 0.026 & 0.003 & -0.12 & 0.069 & 0.07 & -0.20 & 0.07 & 0.007 \\
\hline \multicolumn{10}{|l|}{ Retirement } \\
\hline No & 0 & & & 0 & & & 0 & & \\
\hline Yes & -0.064 & 0.039 & 0.10 & -0.005 & $0 \cdot 11$ & 0.96 & -0.08 & 0.12 & 0.49 \\
\hline \multicolumn{10}{|l|}{ Ethnicity } \\
\hline White & 0 & & & 0 & & & 0 & & \\
\hline South Asian & 0.14 & 0.07 & 0.05 & 0.41 & $0 \cdot 19$ & 0.03 & 0.54 & 0.21 & 0.01 \\
\hline Black & 0.016 & 0.057 & 0.78 & -0.43 & $0 \cdot 15$ & 0.006 & -0.36 & 0.17 & 0.003 \\
\hline Slope (current age) & -0.0025 & 0.0017 & 0.13 & 0.025 & 0.005 & $<0.001$ & 0.022 & 0.0005 & $<0.001$ \\
\hline \multicolumn{10}{|c|}{ Employment grade $\times$ Age } \\
\hline Medium grade & 0.0026 & 0.0013 & 0.05 & -0.0005 & 0.0037 & 0.88 & 0.0020 & 0.0040 & 0.62 \\
\hline Low grade & 0.0009 & 0.0022 & 0.66 & -0.0023 & 0.0061 & 0.71 & -0.0019 & 0.0066 & 0.77 \\
\hline \multicolumn{10}{|l|}{ Sex $\times$ Age } \\
\hline Women & 0.0001 & 0.0015 & 0.94 & -0.0020 & 0.0042 & 0.63 & -0.0007 & 0.0043 & 0.87 \\
\hline \multicolumn{10}{|l|}{ Marital status $\times$ Age } \\
\hline Married & -0.00006 & 0.0015 & 0.97 & -0.0008 & 0.0040 & 0.84 & 0.0015 & 0.0043 & 0.72 \\
\hline \multicolumn{10}{|l|}{ Retirement $\times$ Age } \\
\hline Retired & 0.0018 & 0.0017 & 0.28 & -0.0032 & 0.0047 & 0.49 & -0.0007 & 0.0050 & 0.88 \\
\hline \multicolumn{10}{|l|}{ Ethnicity $\times$ Age } \\
\hline Asian & -0.0004 & 0.0041 & 0.92 & 0.052 & 0.012 & $<0.001$ & 0.051 & 0.012 & $<0.001$ \\
\hline Black & 0.0077 & 0.0030 & 0.01 & 0.010 & 0.008 & 0.23 & 0.014 & 0.0009 & 0.13 \\
\hline
\end{tabular}

* For details of procedures see Subjects and methods.

Sex. Women had statistically significantly lower fried-fish intake and higher recommended-fish and total fish intake than men but the coefficient associated to slope of intake did not differ by sex (Fig. 2 (C)).

Marital and retirement status. While no statistically significant difference appeared for recommended-fish consumption according to marital status, intake of fried fish and total fish in married participants was lower (Fig. 2 (D)). Age-related change in intake was similar for married and non-married participants for all types of fish consumption. Fish consumption and their agerelated trajectories did not differ by retirement status (Fig. 2 (E)).

Ethnicity. Fish consumption and age-related changes showed strong differences according to ethnic group (Fig. 2 (F)). South Asian participants ( $n$ 432) had a higher intake of all types of fish compared with white participants, and the slope of recommended-fish and total fish consumption according to time was significantly higher. Conversely, black participants ( $n$ 275) consumed less recommended and total fish than white participants, and the slope of fried fish intake was statistically significantly higher compared with white participants.

\section{Discussion}

Our report investigates socio-demographic factors associated with fried-fish, recommended-fish (non-fried fish and seafood) and total fish intakes and the age-related trajectories of consumption during later adult life in a prospective cohort of London-based civil servants. Overall, during the 11-year follow-up (1991-2004), a significant increase in consumption of recommended and total fish and a decreasing trend in friedfish intake was observed. A number of the observed trends in fish consumption are consistent with healthy eating recommendations; however it is unclear whether these are direct responses to those recommendations. Mean reported intake of recommended fish is at or above the recommended level. Considering the distribution of intakes, it appears that a sizeable proportion of our study population continues to consume less than the recommended amount of non-fried fish and seafood. Furthermore, we showed that recommended-fish, fried-fish and total fish consumption differed by occupational status, ethnicity, marital status and sex. Of these, only ethnicity had a significant impact on trajectories of age-related fish intake.

We showed that intake of recommended and total fish was higher in women than in men, in South Asian than in white participants, but was lower in black compared with white participants and in low and middle employment grade compared with those in high employment grade. Slope of recommendedfish and total fish intake was higher in South Asian while slope of fried-fish intake was higher in black participants.

To our knowledge, our study is the first to analyse change in age-related trajectories of fish intake according to 
socio-demographic characteristics, such as ethnic group and employment grade, making adjustments for related factors such as sex and marital status. To do this, we applied a random mixed-effect model to track reported consumption across the follow-up period. These models allowed us also to distinguish fish-intake differences according to social characteristics at a given moment (between-subject variation) from individual changes in fish consumption over time (within-subject variation).

Each association between fish consumption trajectories and each socio-demographic factors will now be discussed.

\section{Employment grade}

Participants who were from the clerical and office-support grades (low-grade employment), middle-ranking executive grades (middle-grade) and senior administrative grades (high-grade), differ widely in salary ${ }^{(28)}$. Those in low and middle employment grades had lower intake of fish compared with those in high grades, and specifically a lower intake of recommended and total fish. Our results confirmed those from the literature. Barberger Gateau and colleagues found in the three-city cohort a strong association between income and the dependent variable 'being a regular fish consumer' (at least weekly) ${ }^{(8)}$. Furthermore, dietary energy derived from very-long-chain $n$-3 PUFA, whose main source is fish ${ }^{(34)}$, was found to be higher among white- $v$. blue-collar workers $^{(35)}$. Participants with lower socio-economic status were also found to consume less fish in Swiss adults ${ }^{(36)}$. Finally, fish-eaters included in the Oxford cohort of the European Prospective Investigation into Cancer and Nutrition (EPIC) defined as 'those who do not eat meat but do eat fish' had a higher educational level than 'meat eaters'(10). Our report showed that the age-related increase of fish consumption did not differ between employment grades, suggesting that the social class differences observed for fish consumption were stable. Among middle-grade employment participants who have relatively little financial insecurity, cultural influences may account for some of the difference in food choices ${ }^{(37)}$. Particularly among lower-grade employment participants, lower incomes may limit the purchase of relatively expensive foods such as fish. Lower socio-economic groups tend to buy foods that are cheaper per unit of energy rather than foods rich in protective nutrients ${ }^{(14,20,38,39)}$.

Sex

We found a higher total fish-consumption in women than in men, and that differences were similar over the course of follow-up. More specifically, women reported lower friedfish and higher recommended-fish intakes. These data may reflect healthier eating patterns among women than men in general, including lower fried-food intakes ${ }^{(40,41)}$. One possible reason for these differences relates to health-related nutrition knowledge ${ }^{(42,43)}$.

\section{Ethnic group}

Our study showed a strong link between ethnic group and both baseline levels and trajectories of fish consumption. After controlling for other socio-demographic characteristics, in South
Asian participants, a higher level at baseline and slope of recommended and total fish was observed compared with white participants. Black participants consumed less recommended and total fish at baseline than white participants, and the slope of fried-fish consumption was higher. These results suggest that the heritage of food culture specific to each community is an enduring influence. South Asian participants were predominantly employed in lower-grade employment, and the increasing consumption of fish suggests that food preferences eclipsed the influences of socio-economic position.

\section{Marital and retirement status}

Recommended-fish consumption was similar according to marital status; however non-married participants had a higher intake of fried fish. A previous study found higher fish consumption in married participants which did remain after adjustment for other socio-demographic variables ${ }^{(8)}$. We did not show a relationship between retirement status and fish intake. Neither retirement status nor marital status appear to be determinants of the age-related trajectories of food intake, however we thought that these important lifecourse events should be taken into account in our analysis of food intake tracking.

\section{Conclusion}

Generalisation of our findings is an important consideration. Whitehall II study participants are mainly white, officebased civil servants who were working in London at study baseline. While not representative of the British population as a whole, participants differ considerably in their social origins and in their salaries and work characteristics ${ }^{(44,45)}$. This could explain why the fish consumption is higher in our cohort compared with those observed in the National Diet and Nutritional Survey cohort considered as representative of UK population ${ }^{(7)}$. Furthermore, compared with diary method used in the National Diet and Nutritional Survey to assess food intake, the used of a FFQ in our study may have produced an overestimation of fish consumption.

Another potential limitation is the sample selection throughout follow-up. In our study $24.6 \%$ of participants for whom fish-consumption information was available at inclusion did not complete the two following FFQ, and $25.6 \%$ completed only one. As is classically observed in epidemiological studies, socio-demographic characteristics differed according to FFQ missing data status in our sample. Participants who did not complete all three FFQ were more frequently women, participants in low employment-grade and in an ethnic minority group. However, no significant difference was observed in shellfish or white/oily and total fish consumption between participants who did not complete all the three FFQ and those with complete follow-up.

Our descriptive and analytical work allows a better understanding of impact of socio-demographic factors on fish intake and its age-related trajectory between 1991 and 2004.

While we could not measure the impact of health recommendations emphasising the positive contribution of fish to a healthy diet, the observed consumption trends are consistent with those messages in each of the socio-demographic groups we studied. 


\section{Acknowledgements}

We report no conflict of interest. The Whitehall II study has been supported by grants from UK Medical Research Council, British Heart Foundation, Health and Safety Executive, Department of Health, National Heart Lung and Blood Institute (HL36310), National Institute on Aging (AG13196), Agency for Health Care Policy Research (HS06516); MacArthur Foundation Research Network on Socio-economic Status and Health. No funding source had direct influence over the design, conduct or reporting of this study.

E. J. B. designed the study and contributed to the paper, and T. N. A. carried out the analysis and wrote the first draft.

\section{References}

1. Scientific Advisory Committee on Nutrition (2004) Committee on Toxicity. Advice on Fish Consumption: Benefits and Risks. London: TSO. www.food.gov.uk/multimedia/pdfs/fishreport2004full.pdf.

2. Terry PD, Rohan TE \& Wolk A (2003) Intakes of fish and marine fatty acids and the risks of cancers of the breast and prostate and of other hormone-related cancers: a review of the epidemiologic evidence. Am J Clin Nutr 77, 532-543.

3. Norat T, Bingham S, Ferrari P, Slimani N, Jenab M, Mazuir M, Overvad K, Olsen A, Tjonneland A, et al. (2005) Meat, fish, and colorectal cancer risk: the European Prospective Investigation into cancer and nutrition. J Natl Cancer Inst 97, 906-916.

4. Department of Health (1984) Diet and cardiovascular disease. Committee on Medical Aspects of Food Policy. Report of the Panel on Diet in Relation to Cardiovascular Disease. Rep Health Soc Subj (Lond) 28, 1-32.

5. Department of Health (1994) Nutritional aspects of cardiovascular disease. Committee on Medical Aspects of Food Policy. Report of the Cardiovascular Review Group. Report on Health and Social Subjects. London: HMSO

6. Scientific Advisory Committee on Nutrition (2004) Advice on Fish Consumption: Benefits and Risks. London: TSO.

7. Henderson L, Gregory J \& Swan G (2002) The National Diet and Nutrition Survey: adults aged 19 to 64 years. Vol. 1: Types and Quantities of Foods Consumed. London: TSO.

8. Barberger-Gateau P, Jutand MA, Letenneur L, Larrieu S, Tavernier B \& Berr C (2005) Correlates of regular fish consumption in French elderly community dwellers: data from the Three-City study. Eur J Clin Nutr 59, 817-825.

9. Burger J, Boring S, Dixon C, Lord C, McMahon M, Ramos R, Shukla S, Jeitner C \& Gochfeld M (2002) Exposure of South Carolinians to commercial meats and fish within their meat and fish diet. Sci Total Environ 287, 71-81.

10. Davey GK, Spencer EA, Appleby PN, Allen NE, Knox KH \& Key TJ (2003) EPIC-Oxford: lifestyle characteristics and nutrient intakes in a cohort of 33883 meat-eaters and 31546 non meat-eaters in the UK. Public Health Nutr 6, 259-269.

11. Welch AA, Lund E, Amiano P, et al. (2002) Variability of fish consumption within the 10 European countries participating in the European Investigation into Cancer and Nutrition (EPIC) study. Public Health Nutr 5, 1273-1285.

12. Giskes K, Turrell G, van Lenthe FJ, Brug J \& Mackenbach JP (2006) A multilevel study of socio-economic inequalities in food choice behaviour and dietary intake among the Dutch population: the GLOBE study. Public Health Nutr 9, 75-83.

13. Hulshof KF, Brussaard JH, Kruizinga AG, Telman J \& Lowik MR (2003) Socio-economic status, dietary intake and 10 year trends: the Dutch National Food Consumption Survey. Eur J Clin Nutr 57, 128-137.
14. James WP, Nelson M, Ralph A \& Leather S (1997) Socioeconomic determinants of health. The contribution of nutrition to inequalities in health. Br Med J 314, 1545-1549.

15. Lopez-Azpiazu I, Sanchez-Villegas A, Johansson L, Petkeviciene J, Prattala R \& Martinez-Gonzalez MA (2003) Disparities in food habits in Europe: systematic review of educational and occupational differences in the intake of fat. J Hum Nutr Diet 16, 349-364.

16. Prattala R, Berg MA \& Puska P (1992) Diminishing or increasing contrasts? Social class variation in Finnish food consumption patterns, 1979-1990. Eur J Clin Nutr 46, 279-287.

17. Shahar D, Shai I, Vardi H, Shahar A \& Fraser D (2005) Diet and eating habits in high and low socioeconomic groups. Nutrition 21, 559-566.

18. Shimakawa T, Sorlie P, Carpenter MA, Dennis B, Tell GS, Watson R \& Williams OD (1994) Dietary intake patterns and sociodemographic factors in the atherosclerosis risk in communities study. ARIC Study Investigators. Prev Med 23, 769-780.

19. Woo J, Leung SS, Ho SC, Sham A, Lam TH \& Janus ED (1999) Influence of educational level and marital status on dietary intake, obesity and other cardiovascular risk factors in a Hong Kong Chinese population. Eur J Clin Nutr 53, 461-467.

20. Smith GD \& Brunner EJ (1997) Socioeconomic differentials in health: the role of nutrition. Proc Nutr Soc 56, 75-90.

21. Hjartaker A \& Lund E (1998) Relationship between dietary habits, age, lifestyle, and socio-economic status among adult Norwegian women. The Norwegian Women and Cancer Study. Eur J Clin Nutr 52, 565-572.

22. Bates CJ, Prentice A \& Finch S (1999) Gender differences in food and nutrient intakes and status indices from the National Diet and Nutrition Survey of people aged 65 years and over. Eur J Clin Nutr 53, 694-699.

23. Milligan RA, Burke V, Beilin LJ, Dunbar DL, Spencer MJ, Balde E \& Gracey MP (1998) Influence of gender and socioeconomic status on dietary patterns and nutrient intakes in 18-year-old Australians. Aust N Z J Public Health 22, 485-493.

24. Bhopal R, Hayes L, White M, Unwin N, Harland J, Ayis S \& Alberti G (2002) Ethnic and socio-economic inequalities in coronary heart disease, diabetes and risk factors in Europeans and South Asians. J Public Health Med 24, 95-105.

25. Cornelisse-Vermaat JR \& van den Brink HM (2007) Ethnic differences in lifestyle and overweight in The Netherlands. Obesity (Silver Spring) 15, 483-493.

26. Whichelow MJ \& Prevost AT (1996) Dietary patterns and their associations with demographic, lifestyle and health variables in a random sample of British adults. Br J Nutr 76, 17-30.

27. Marmot MG, Smith GD, Stansfeld S, Patel C, North F, Head J, White I, Brunner E \& Feeney A (1991) Health inequalities among British civil servants: the Whitehall II study. Lancet 337, 1387-1393.

28. Marmot M \& Brunner E (2005) Cohort Profile: the Whitehall II study. Int J Epidemiol 34, 251-256.

29. Brunner E, Stallone D, Juneja M, Bingham S \& Marmot M (2001) Dietary assessment in Whitehall II: comparison of $7 \mathrm{~d}$ diet diary and food-frequency questionnaire and validity against biomarkers. Br J Nutr 86, 405-414.

30. Willett WC, Sampson L, Stampfer MJ, Rosner B, Bain C, Witschi J, Hennekens CH \& Speizer FE (1985) Reproducibility and validity of a semiquantitative food frequency questionnaire. Am J Epidemiol 122, 51-65.

31. Bingham SA, Gill C, Welch A, et al. (1997) Validation of dietary assessment methods in the UK arm of EPIC using weighed records, and 24-hour urinary nitrogen and potassium and serum vitamin $\mathrm{C}$ and carotenoids as biomarkers. Int $J$ Epidemiol 26, Suppl. 1, S137-S151.

32. Diggle P, Heargerty P, Liang KY \& Zeger S (2002) Analysis of Longitudinal Data, 2nd ed. United States: Oxford University Press. 
33. Jacobs DR Jr, Hannan PJ, Wallace D, Liu K, Williams OD \& Lewis CE (1999) Interpreting age, period and cohort effects in plasma lipids and serum insulin using repeated measures regression analysis: the CARDIA Study. Stat Med 18, 655-679.

34. Astorg P, Arnault N, Czernichow S, Noisette N, Galan P \& Hercberg S (2004) Dietary intakes and food sources of $n-6$ and $n$-3 PUFA in French adult men and women. Lipids 39, $527-535$.

35. Johansson LR, Solvoll K, Bjorneboe GE \& Drevon CA (1998) Intake of very-long-chain $n-3$ fatty acids related to social status and lifestyle. Eur J Clin Nutr 52, 716-721.

36. Galobardes B, Morabia A \& Bernstein MS (2001) Diet and socioeconomic position: does the use of different indicators matter? Int J Epidemiol 30, 334-340.

37. Montanari M (1996) The Culture of Food. Blackwell: Oxford.

38. Dowler EA (1997) Budgeting for food on a low income in the UK: the case of lone-parent families. Food Policy 22, 405-417.

39. Stallone DD, Brunner EJ, Bingham SA \& Marmot MG (1997) Dietary assessment in Whitehall II. The influence of reporting bias on apparent socioeconomic variation in nutrient intakes. Eur J Clin Nutr 51, 815-825.

40. Pryer JA, Brunner EJ, Elliott P, Nichols R, Dimond H \& Marmot MG (1995) Who complied with COMA 1984 dietary fat recommendations among a nationally representative sample of British adults in 1986-7 and what do they eat? Eur J Clin Nutr 49, 718-728.

41. Martikainen P, Brunner E \& Marmot M (2003) Socioeconomic differences in dietary patterns among middle-aged men and women. Soc Sci Med 56, 1397-1410.

42. Parmenter K, Waller J \& Wardle J (2000) Demographic variation in nutrition knowledge in England. Health Educ Res 15, 163-174.

43. Baker AH \& Wardle J (2003) Sex differences in fruit and vegetable intake in older adults. Appetite 40, 269-275.

44. Marmot MG \& Brunner EJ (2005) Cohort Profile: the Whitehall II study. Int J Epidemiol 34, 251-256.

45. Marmot MG, Davey Smith G, Stansfeld SA, Patel C, North F, Head J, White I, Brunner EJ \& Feeney A (1991) Health inequalities among British Civil Servants: the Whitehall II study. Lancet 337, 1387-1393. 


\section{Appendix}

\section{Random-effect model}

The random-effects models, also called hierarchical, or multilevel model, were fitted using the SAS 9.1 software package.

$$
Y_{i j}=\beta_{\mathrm{I}}+b_{i 0}+\left(\beta_{\mathrm{p}}+b_{i 1}\right) \times \text { Current Age }+e_{i j}
$$

where $Y_{i j}$ is fish consumption for the subject $i$ at the time $j$; Current Age is age at phase $3+$ time of follow-up. $\beta$ is fixed parameters of the population: $\beta_{\mathrm{I}}$, intercept in the population; $\beta_{\mathrm{p}}$, slope in the population. $b_{i 0}$ and $b_{i 1}$ are the random effects modelising the heterogeneity of individual in the population due to latent factors: $b_{i 0}$, the difference between intercept of the subject $i$ and intercept of the population; $b_{i 1}$, the difference between slope of the subject $i$ and slope of the population.

\section{SAS model}

proc mixed order $=$ formatted data $=$ x.dsmixclf noclprint method $=\mathrm{ml}$;

class stno Employment_Grade Sex Marital_Status Retirement_Status Ethnicity;

model fish = Employment_Grade Current_Age Sex Marital_Status Retirement_Status Ethnicity

Employment_Grade $\times$ Current_Age Sex $\times$ Current_Age Marital_Status $\times$ Current_Age Retirement_Status $\times$ Current_ Age Ethnicity $\times$ Current_Age/solution ddfm $=$ satterth;

random intercept Current_Age/type $=$ un subject $=$ stno; run; (stmo: study number of participants) 
Appendix Table 1. Fried fish consumption (portion/week) in Whitehall participants, 1991-2004 (Values are means with standard deviations for $n$ participants)

\begin{tabular}{|c|c|c|c|c|c|c|c|c|c|c|c|c|c|c|c|c|c|c|}
\hline & \multicolumn{9}{|c|}{ Men } & \multicolumn{9}{|c|}{ Women } \\
\hline & \multicolumn{3}{|c|}{ Phase 3} & \multicolumn{3}{|c|}{ Phase 5} & \multicolumn{3}{|c|}{ Phase 7} & \multicolumn{3}{|c|}{ Phase 3} & \multicolumn{3}{|c|}{ Phase 5} & \multicolumn{3}{|c|}{ Phase 7} \\
\hline & Mean & SD & $n$ & Mean & SD & $n$ & Mean & SD & $n$ & Mean & SD & $n$ & Mean & SD & $n$ & Mean & SD & $n$ \\
\hline \multicolumn{19}{|l|}{ Age group } \\
\hline $39-44$ & 0.51 & 0.63 & 1550 & & & & & & & 0.41 & 0.68 & 575 & & & & & & \\
\hline $45-49$ & 0.50 & 0.61 & 1619 & 0.54 & 0.68 & 807 & & & & 0.40 & 0.69 & 640 & 0.42 & 0.56 & 281 & & & \\
\hline $50-54$ & 0.51 & 0.66 & 1130 & 0.50 & 0.59 & 1086 & 0.50 & 0.60 & 714 & 0.39 & 0.66 & 564 & 0.37 & 0.56 & 392 & 0.28 & 0.43 & 269 \\
\hline $55-59$ & 0.48 & 0.63 & 1171 & 0.52 & 0.86 & 776 & 0.46 & 0.60 & 1233 & 0.44 & 0.69 & 647 & 0.44 & 0.74 & 350 & 0.35 & 0.50 & 426 \\
\hline $60-64$ & 0.51 & 0.75 & 272 & 0.54 & 0.81 & 823 & 0.43 & 0.59 & 855 & 0.39 & 0.49 & 160 & 0.39 & 0.57 & 369 & 0.35 & 0.60 & 347 \\
\hline $65-69$ & & & & 0.47 & 0.63 & 314 & 0.44 & 0.58 & 815 & & & & 0.48 & 0.75 & 131 & 0.44 & 0.53 & 365 \\
\hline $70-75$ & & & & & & & 0.48 & 0.62 & 377 & & & & & & & 0.44 & 0.57 & 159 \\
\hline \multicolumn{19}{|c|}{ Employment grade } \\
\hline High & 0.44 & 0.55 & 2746 & 0.47 & 0.63 & 2061 & 0.41 & 0.53 & 2254 & 0.28 & 0.51 & 399 & 0.27 & 0.44 & 323 & 0.25 & 0.39 & 360 \\
\hline Middle & 0.53 & 0.66 & 2561 & 0.55 & 0.80 & 1561 & 0.49 & 0.63 & 1598 & 0.36 & 0.51 & 1151 & 0.41 & 0.61 & 717 & 0.39 & 0.59 & 783 \\
\hline Low & 0.72 & 0.89 & 378 & 0.77 & 0.95 & 167 & 0.82 & 0.99 & 132 & 0.51 & 0.85 & 1005 & 0.49 & 0.79 & 474 & 0.43 & 0.50 & 408 \\
\hline \multicolumn{19}{|l|}{ Marital status } \\
\hline Not married & 0.62 & 0.81 & 999 & 0.64 & 1.06 & 618 & 0.58 & 0.78 & 660 & 0.41 & 0.71 & 939 & 0.44 & 0.70 & 576 & 0.37 & 0.52 & 663 \\
\hline Married & 0.48 & 0.59 & 4691 & 0.49 & 0.62 & 3134 & 0.43 & 0.55 & 3324 & 0.40 & 0.64 & 1614 & 0.39 & 0.54 & 883 & 0.36 & 0.54 & 891 \\
\hline \multicolumn{19}{|l|}{ Retirement } \\
\hline No & 0.51 & 0.63 & 5183 & 0.53 & 0.68 & 2741 & 0.47 & 0.61 & 2269 & 0.42 & 0.69 & 2314 & 0.40 & 0.62 & 1025 & 0.34 & 0.49 & 750 \\
\hline Yes & 0.46 & 0.64 & 565 & 0.49 & 0.83 & 1039 & 0.44 & 0.58 & 1715 & 0.28 & 0.50 & 275 & 0.42 & 0.63 & 480 & 0.39 & 0.56 & 804 \\
\hline \multicolumn{19}{|l|}{ Ethnicity } \\
\hline White & 0.49 & 0.61 & 5328 & 0.50 & 0.68 & 3608 & 0.45 & 0.59 & 3796 & 0.38 & 0.52 & 2212 & 0.40 & 0.57 & 1359 & 0.35 & 0.49 & 1397 \\
\hline South Asian & 0.75 & 0.97 & 277 & 0.86 & 1.29 & 144 & 0.60 & 0.74 & 147 & 0.45 & 0.77 & 156 & 0.47 & 0.56 & 73 & 0.41 & 0.45 & 78 \\
\hline Black & 0.63 & 0.83 & 99 & 0.74 & 1.32 & 41 & 0.55 & 0.91 & 40 & 0.62 & 1.51 & 173 & 0.59 & 1.24 & 77 & 0.50 & 0.96 & 71 \\
\hline
\end{tabular}


Appendix Table 2. Recommended fish* consumption (portion/week) in Whitehall participants, 1991-2004

(Values are means with standard deviations for $n$ participants)

\begin{tabular}{|c|c|c|c|c|c|c|c|c|c|c|c|c|c|c|c|c|c|c|}
\hline & \multicolumn{9}{|c|}{ Men } & \multicolumn{9}{|c|}{ Women } \\
\hline & \multicolumn{3}{|c|}{ Phase 3} & \multicolumn{3}{|c|}{ Phase 5} & \multicolumn{3}{|c|}{ Phase 7} & \multicolumn{3}{|c|}{ Phase 3} & \multicolumn{3}{|c|}{ Phase 5} & \multicolumn{3}{|c|}{ Phase 7} \\
\hline & Mean & SD & $n$ & Mean & SD & $n$ & Mean & SD & $n$ & Mean & SD & $n$ & Mean & SD & $n$ & Mean & SD & $n$ \\
\hline \multicolumn{19}{|l|}{ Age group } \\
\hline $39-44$ & 1.6 & 1.5 & 1549 & & & & & & & $2 \cdot 0$ & 1.9 & 574 & & & & & & \\
\hline $45-49$ & 1.7 & 1.7 & 1618 & $1 \cdot 8$ & 1.7 & 807 & & & & $2 \cdot 2$ & $2 \cdot 0$ & 640 & $2 \cdot 2$ & 1.9 & 280 & & & \\
\hline $50-54$ & 1.7 & 1.8 & 1132 & 1.8 & 1.7 & 1096 & 1.9 & 1.6 & 720 & $2 \cdot 0$ & $2 \cdot 1$ & 567 & 2.5 & $2 \cdot 9$ & 398 & $2 \cdot 4$ & $2 \cdot 1$ & 272 \\
\hline $55-59$ & 1.9 & 1.7 & 1172 & $2 \cdot 0$ & 1.7 & 779 & 2.0 & 1.8 & 1244 & $2 \cdot 2$ & $2 \cdot 3$ & 649 & 2.3 & $2 \cdot 2$ & 351 & $2 \cdot 7$ & $2 \cdot 0$ & 429 \\
\hline $60-64$ & 1.9 & 1.8 & 273 & 2.0 & 1.7 & 829 & $2 \cdot 2$ & 1.8 & 867 & 1.7 & 1.7 & 160 & 2.4 & 2.5 & 375 & $2 \cdot 7$ & $2 \cdot 3$ & 350 \\
\hline $65-69$ & & & & 1.91 & 1.7 & 319 & $2 \cdot 1$ & 1.6 & 821 & & & & $2 \cdot 2$ & $2 \cdot 1$ & 132 & $2 \cdot 4$ & 1.9 & 368 \\
\hline $70-75$ & & & & & & & 2.3 & 2.0 & 381 & & & & & & & $2 \cdot 6$ & $2 \cdot 8$ & 161 \\
\hline \multicolumn{19}{|c|}{ Employment grade } \\
\hline High & $2 \cdot 0$ & 1.8 & 2746 & $2 \cdot 1$ & 1.8 & 2074 & $2 \cdot 3$ & $1 \cdot 8$ & 2276 & 2.5 & 1.9 & 397 & $2 \cdot 7$ & $2 \cdot 1$ & 325 & 2.9 & $2 \cdot 1$ & 362 \\
\hline Middle & 1.5 & 1.5 & 2563 & 1.7 & 1.7 & 1575 & 1.8 & 1.7 & 1613 & $2 \cdot 2$ & $2 \cdot 0$ & 1152 & $2 \cdot 3$ & $2 \cdot 6$ & 727 & $2 \cdot 6$ & $2 \cdot 3$ & 790 \\
\hline Low & 1.4 & 1.7 & 377 & $1 \cdot 8$ & 1.9 & 165 & 2.0 & $2 \cdot 1$ & 133 & 1.9 & $2 \cdot 1$ & 1008 & $2 \cdot 2$ & $2 \cdot 3$ & 475 & $2 \cdot 2$ & 2.0 & 413 \\
\hline \multicolumn{19}{|l|}{ Marital status } \\
\hline Not married & 1.7 & 1.8 & 999 & 1.9 & 1.8 & 623 & $2 \cdot 2$ & $2 \cdot 1$ & 663 & $2 \cdot 2$ & $2 \cdot 2$ & 939 & 2.4 & $2 \cdot 7$ & 582 & $2 \cdot 6$ & $2 \cdot 2$ & 666 \\
\hline Married & $1 \cdot 7$ & 1.6 & 4692 & 1.9 & 1.7 & 3152 & $2 \cdot 1$ & 1.7 & 3360 & $2 \cdot 1$ & 2.0 & 1616 & $2 \cdot 4$ & $2 \cdot 1$ & 890 & 2.5 & $2 \cdot 2$ & 902 \\
\hline \multicolumn{19}{|l|}{ Retirement } \\
\hline No & 1.7 & 1.7 & 5184 & 1.9 & 1.8 & 2759 & $2 \cdot 1$ & 1.7 & 2293 & $2 \cdot 1$ & 2.0 & 2320 & 2.4 & 2.4 & 1034 & $2 \cdot 6$ & $2 \cdot 1$ & 752 \\
\hline Yes & 1.8 & 1.7 & 566 & $2 \cdot 0$ & 1.7 & 1048 & $2 \cdot 1$ & $1 \cdot 8$ & 1730 & $2 \cdot 0$ & $2 \cdot 3$ & 275 & $2 \cdot 3$ & $2 \cdot 4$ & 484 & 2.5 & $2 \cdot 2$ & 816 \\
\hline \multicolumn{19}{|l|}{ Ethnicity } \\
\hline White & $1 \cdot 7$ & 1.6 & 5330 & 1.9 & 1.7 & 3629 & $2 \cdot 1$ & 1.7 & 3830 & $2 \cdot 1$ & 1.9 & 2216 & $2 \cdot 3$ & $2 \cdot 1$ & 1371 & 2.5 & $2 \cdot 0$ & 1409 \\
\hline South Asian & 1.3 & 1.9 & 276 & 1.8 & $2 \cdot 3$ & 146 & 1.7 & $1 \cdot 8$ & 150 & $1 \cdot 7$ & 1.9 & 156 & 1.7 & 1.9 & 74 & $2 \cdot 1$ & $2 \cdot 1$ & 77 \\
\hline Black & $2 \cdot 2$ & $2 \cdot 1$ & 100 & 2.9 & 3.2 & 42 & $3 \cdot 2$ & 3.0 & 41 & 3.0 & 3.4 & 175 & 4.0 & $5 \cdot 8$ & 77 & 4.0 & 3.7 & 74 \\
\hline
\end{tabular}

*White and oily fish, and shellfish. 
Appendix Table 3. Total fish consumption (portion/week) in Whitehall participants, 1991-2004 (Values are means with standard deviations for $n$ participants)

\begin{tabular}{|c|c|c|c|c|c|c|c|c|c|c|c|c|c|c|c|c|c|c|}
\hline & \multicolumn{9}{|c|}{ Men } & \multicolumn{9}{|c|}{ Women } \\
\hline & \multicolumn{3}{|c|}{ Phase 3} & \multicolumn{3}{|c|}{ Phase 5} & \multicolumn{3}{|c|}{ Phase 7} & \multicolumn{3}{|c|}{ Phase 3} & \multicolumn{3}{|c|}{ Phase 5} & \multicolumn{3}{|c|}{ Phase 7} \\
\hline & Mean & SD & $n$ & Mean & SD & $n$ & Mean & SD & $n$ & Mean & SD & $n$ & Mean & SD & $n$ & Mean & SD & $n$ \\
\hline \multicolumn{19}{|l|}{ Age group } \\
\hline $39-44$ & $2 \cdot 1$ & 1.7 & 1549 & & & & & & & 2.5 & $2 \cdot 0$ & 574 & & & & & & \\
\hline $45-49$ & $2 \cdot 2$ & 1.8 & 1618 & $2 \cdot 3$ & 1.92 & 805 & & & & $2 \cdot 6$ & $2 \cdot 1$ & 640 & $2 \cdot 6$ & $2 \cdot 1$ & 279 & & & \\
\hline $50-54$ & $2 \cdot 3$ & 1.9 & 1129 & $2 \cdot 3$ & 1.88 & 1083 & $2 \cdot 4$ & 1.8 & 711 & 2.4 & $2 \cdot 3$ & 563 & 2.9 & $2 \cdot 9$ & 392 & 2.77 & $2 \cdot 2$ & 267 \\
\hline $55-59$ & $2 \cdot 3$ & 1.9 & 1170 & $2 \cdot 5$ & 1.99 & 773 & 2.5 & 1.9 & 1228 & $2 \cdot 6$ & $2 \cdot 4$ & 646 & $2 \cdot 8$ & $2 \cdot 4$ & 349 & $3 \cdot 1$ & $2 \cdot 1$ & 423 \\
\hline $60-64$ & 2.5 & 1.9 & 272 & $2 \cdot 6$ & 1.92 & 820 & $2 \cdot 6$ & 1.9 & 853 & 2.4 & 1.7 & 160 & $2 \cdot 8$ & 2.5 & 369 & 3.1 & $2 \cdot 4$ & 346 \\
\hline $65-69$ & & & & $2 \cdot 4$ & $1 \cdot 88$ & 314 & 2.5 & 1.7 & 808 & & & & $2 \cdot 7$ & $2 \cdot 2$ & 131 & $2 \cdot 8$ & $2 \cdot 0$ & 363 \\
\hline $70-75$ & & & & & & & $2 \cdot 8$ & $2 \cdot 1$ & 373 & & & & & & & 3.0 & $2 \cdot 8$ & 158 \\
\hline \multicolumn{19}{|c|}{ Employment grade } \\
\hline High & 2.4 & 1.9 & 2745 & 2.57 & 1.88 & 2057 & $2 \cdot 68$ & 1.67 & 2243 & 2.77 & 2.00 & 397 & 2.95 & $2 \cdot 16$ & 322 & 3.17 & $2 \cdot 16$ & 358 \\
\hline Middle & 2.0 & 1.7 & 2560 & $2 \cdot 23$ & 1.92 & 1559 & $2 \cdot 33$ & 1.82 & 1589 & 2.54 & 2.09 & 1151 & $2 \cdot 76$ & 2.65 & 717 & 2.95 & $2 \cdot 41$ & 779 \\
\hline Low & $2 \cdot 1$ & $2 \cdot 0$ & 376 & 2.59 & $2 \cdot 15$ & 163 & $2 \cdot 75$ & $2 \cdot 36$ & 131 & 2.42 & 2.44 & 1005 & $2 \cdot 70$ & 2.46 & 472 & $2 \cdot 65$ & 2.09 & 4050 \\
\hline \multicolumn{19}{|l|}{ Marital status } \\
\hline Not married & $2 \cdot 3$ & $2 \cdot 0$ & 998 & 2.55 & $2 \cdot 14$ & 613 & $2 \cdot 76$ & $2 \cdot 19$ & 655 & $2 \cdot 61$ & $2 \cdot 30$ & 939 & $2 \cdot 83$ & 2.84 & 575 & 2.94 & $2 \cdot 31$ & 658 \\
\hline Married & $2 \cdot 2$ & 1.8 & 4688 & $2 \cdot 41$ & 1.86 & 3128 & $2 \cdot 50$ & 1.80 & 3308 & 2.48 & $2 \cdot 18$ & 1612 & $2 \cdot 76$ & $2 \cdot 17$ & 882 & 2.91 & $2 \cdot 26$ & 887 \\
\hline \multicolumn{19}{|l|}{ Retirement } \\
\hline No & $2 \cdot 2$ & 1.8 & 5180 & 2.42 & 1.92 & 2735 & 2.54 & 1.86 & 2261 & 2.55 & $2 \cdot 20$ & 2311 & $2 \cdot 79$ & 2.52 & 1022 & 2.93 & $2 \cdot 25$ & 745 \\
\hline Yes & $2 \cdot 31$ & 1.83 & 564 & 2.45 & 1.93 & 1035 & 2.54 & 1.91 & 1702 & 2.35 & $2 \cdot 31$ & 275 & $2 \cdot 74$ & 2.45 & 480 & 2.90 & $2 \cdot 28$ & 801 \\
\hline \multicolumn{19}{|l|}{ Ethnicity } \\
\hline White & $2 \cdot 22$ & 1.78 & 5325 & 2.40 & 1.83 & 3599 & 2.54 & 1.85 & 3778 & 2.47 & 1.96 & 2210 & $2 \cdot 70$ & $2 \cdot 13$ & 1357 & $2 \cdot 85$ & $2 \cdot 12$ & 1391 \\
\hline South Asian & 2.04 & $2 \cdot 26$ & 276 & $2 \cdot 64$ & $2 \cdot 80$ & 142 & 2.26 & $2 \cdot 12$ & 143 & $2 \cdot 11$ & $2 \cdot 28$ & 156 & $2 \cdot 16$ & $2 \cdot 18$ & 73 & $2 \cdot 46$ & $2 \cdot 27$ & 75 \\
\hline Black & $2 \cdot 88$ & $2 \cdot 31$ & 99 & 3.67 & $4 \cdot 10$ & 41 & 3.68 & $3 \cdot 10$ & 40 & 3.57 & 4.11 & 172 & 4.57 & 5.90 & 76 & 4.55 & 3.94 & 71 \\
\hline
\end{tabular}

